\title{
A Method for Estimating Economic Injury Levels for Control of Rangeland Grass- hoppers with Malathion and Carbaryl
}

\author{
JEROME A. ONSAGER
}

\begin{abstract}
A theoretical "average" rangeland grasshopper weighs $81.6 \mathrm{mg}$ (dry weight) in the adult stage and consumes 9,22 , and $53 \mathrm{mg}$ of forage/day in the 4th instar, 5th instar, and adult stages, respectively. Criteria for a computer program are presented whereby grazing pressure from grasshopper infestations can be predicted as a function of initial density and normal dally rate of survival. The benefits of a contemplated control measure may then be estimated through appropriate adjustment of the survival rate. By assigning dollar values to the worth of forage and cost of treatment, the lowest infestation that will justify control measures can be determined. The technique is demonstrated for 2 effective but dissimilar insecticides, malathion and carbaryl. By using actual treatment costs for 1981 control programs and by assuming that an AUM (364 kg of forage) saved from destruction by grasshoppers has a marginal value product of S14, it was calculated that grazing by grasshoppers must approach $0.25 \mathrm{AUM} / \mathrm{ha}$ before treatment becomes economical. If treatments are not applied before carrying capacity has been depleted by grasshoppers, then the forage that is saved cannot be harvested. Thus, early treatments with both chemicals are much more economical than late treatments.
\end{abstract}

Stern et al. (1959) defined the economic injury level (EIL) of a pest insect as "the lowest population density that will cause economic damage," where economic damage is "the amount of injury which will justify the cost of artificial control measures." In theory, the EIL concept has been widely accepted among entomologists as the economic basis for rational pest management. In practice, however, ElLs have often been among the weakest components in management programs (Poston et al. 1983). On rangeland, for example, cooperative Federal-State-private grasshopper control programs administered by USDA's Animal and Plant Health Inspection Service (APHIS) have traditionally required an average density of 9.6 or more grasshoppers $/ \mathrm{m}^{2}$. That level is strictly an administrative guideline, and it obviously does not consider such factors as cost, potency, persistence, or time of application, all of which vary considerably among alternative treatments.

The objectives of this paper are to provide a method for estimat-

Author is with the Rangeland Insect Laboratory, Agricultural Research Service, USDA, Bozeman, Mont. 59717.

Manuscript received November 12, 1982. ing EILs for grasshoppers on range, and to report relationships between efficacy and time of application for 2 effective but dissimilar treatments, malathion and carbaryl. Except for information on costs of treatments, all data for this study were available in published literature but required modification, extended interpretation, and synthesis.

\section{Materials and Methods}

\section{Forage Destruction Potential}

The rate at which an infestation of grasshoppers destroys forage is a highly variable function of species composition, stage of development, and rate of survival over time (Capinera et al. 1982, Onsager 1983). Most destructive grasshopper species have 5 nymphal instars. It is most probable that the first 3 instars will be responsible for only about $15-20 \%$ of the total forage utilization by a generation of grasshoppers (Onsager 1983). The first 2 instars usually are of little consequence, but the 3rd tends to become important for 3 reasons: (1) it begins to consume forage at a significant rate, (2) its appearance coincides with maturation of important cool-season grasses so forage losses may not be replaced by regrowth, and (3) the probability of catastrophic mortality becomes relatively low (Hewitt 1979). Because the majority of grasshoppers must attain the 3 rd instar before one can confidently diagnose an economic infestation and bring control measures to bear, forage utilization by that stage must be conceded. In subsequent discussion, therefore, the destructive period will by definition begin with appearance of the 4th instar, against which control tactics definitely are feasible.

In a recent study of potential forage losses, Hewitt and Onsager (1982) divided grasshopper species into 3 size classes on the basis of dry body weight. Their infestations over a 3 -year period were comprised of an average of 40,55 , and $5 \%$ small, medium, and large species, respectively. Important destructive species whose weight closely approximated average weights for the 3 size classes were Ageneotettix deorum (Scudder) and Melanoplus infantilis Scudder, Aulocara elliotti (Thomas) and M. sanguinipes (Say), and $M$. bivittatus (Say), respectively. The adult grasshoppers destroyed forage equivalent to an average of 0.65 times their weight each day. For the current study, it was determined that a theoreti- 
Table 1. Relations between density of young $4 \mathrm{th}$ instar grasshoppers, natural average daily rates of survival, and potential grazing intensity.

\begin{tabular}{|c|c|c|c|c|c|c|c|c|c|}
\hline \multirow{4}{*}{$\begin{array}{l}\text { Density } \\
\left.\text { (no. } / \mathrm{m}^{2}\right)\end{array}$} & \multirow{4}{*}{$\begin{array}{l}\text { Daily } \\
\text { survival } \\
\text { rate }\end{array}$} & \multicolumn{8}{|c|}{ Instar or stage } \\
\hline & & \multicolumn{2}{|c|}{ 4th instar } & \multicolumn{2}{|c|}{ 5th instar } & \multicolumn{2}{|c|}{ Adult } & & \\
\hline & & \multirow[b]{2}{*}{$\mathrm{GHD} / \mathrm{m}^{2}$} & \multirow{2}{*}{$\begin{array}{c}\text { Forage } \\
\text { consumed } \\
(\mathrm{kg} / \mathrm{ha})\end{array}$} & \multirow[b]{2}{*}{$\mathrm{GHD} / \mathrm{m}^{2}$} & \multirow{2}{*}{$\begin{array}{l}\text { Forage } \\
\text { consumed } \\
(\mathrm{kg} / \mathrm{ha})\end{array}$} & \multirow[b]{2}{*}{$\mathrm{GHD} / \mathrm{m}^{2}$} & \multirow{2}{*}{$\begin{array}{c}\text { Forage } \\
\text { consumed } \\
(\mathrm{kg} / \mathrm{ha})\end{array}$} & \multicolumn{2}{|c|}{$\begin{array}{c}\text { Total grazing } \\
\text { intensity }\end{array}$} \\
\hline & & & & & & & & $\mathrm{kg} / \mathrm{ha}$ & AUM/ha \\
\hline 4 & 0.98550 & 33.8 & 3.0 & 29.6 & 6.5 & 154.8 & 82.1 & 91.6 & 0.25 \\
\hline 6 & .98156 & 49.7 & 4.5 & 42.0 & 9.3 & 188.2 & 99.7 & 113.5 & .31 \\
\hline 8 & .97833 & 64.7 & 5.8 & 53.1 & 11.7 & 211.7 & 112.2 & 129.7 & .36 \\
\hline 16 & .96972 & 124.0 & 11.2 & 94.4 & 20.8 & 280.8 & 148.8 & 180.8 & .50 \\
\hline 32 & .95999 & 235.9 & 21.2 & 163.0 & 35.9 & 356.0 & 188.7 & 245.8 & .68 \\
\hline
\end{tabular}

cal "representative" adult of a population comprised of the above proportions and species would weigh $81.6 \mathrm{mg}$ (dry weight) and would destroy $53 \mathrm{mg}$ (i.e., $81.6 \times 0.65$ ) of forage/day. Because daily forage destruction increases by a factor of 2.42 with each successive molt (Onsager 1983), the average daily rate for representative 4th and 5th instar nymphs was set at 9 and $22 \mathrm{mg}$, respectively.

Hewitt and Onsager (1982) estimated the destructive potential of untreated populations of grasshoppers by assuming constant average rates of survival and forage destruction for predominant species. It was later determined that because survival rates were adversely affected by density (Onsager et al. 1981), nymphs consumed proportionately more forage under high density conditions than under low densities (Capinera et al. 1982, Onsager 1983). Therefore, a more accurate method for estimating destructive potential is as follows. The average daily survival rate (S) is calculated as a function of density (D) of $4 \mathrm{th}$ instar nymphs $/ \mathrm{m}^{2}$ according to the formula, $\ln \mathrm{S}=-0.0028909-0.0064462(\ln \mathrm{D})-0.0012987(\ln \mathrm{D})^{2}$ (an elaboration of Table 2, Onsager 1983). For any given density of 4th instar grasshoppers $/ \mathrm{m}^{2}$, the number of survivors is plotted versus time, according to the formula $D_{i}=D_{0}\left(S^{i}\right)$, where $D_{i}=$ density of survivors on the $i$ th day, $D_{0}=$ initial density of 4th instar nymphs, $\mathrm{S}=$ daily survival rate, and $i=$ no. of days after beginning of the 4th instar. Assuming that representative nymphal instars require 9 days each and no adults survive beyond 90 days, the areas under the survival curve for 4th instars, 5 th instars, and adults are determined separately by the trapazoid method of numerical integration. These areas are the products of grasshoppers multiplied by time, and the units are designated grasshopper days (GHD). The GHD for each development period is multiplied by the appropriate average daily rate of forage destruction, and the summation of the 3 products is the total potential forage destruction per $\mathrm{m}^{2}$. The total potential forage destruction $/ \mathrm{m}^{2}$ associated with 5 selected population densities is illustrated in Table 1 . The benefits of a contemplated treatment may then be estimated by adjusting the survival curve according to anticipated effects of treatment, calculating the
GHD and associated forage destruction under the new curve, and attributing the difference to benefits of treatment (Onsager 1978).

\section{Efficacy of Malathion}

Table 2 summarizes results from 4 experiments between 1976 and 1979 where the author and a coworker applied $584 \mathrm{ml}$ of $95 \%$ technical malathion/ha to grasshopper-infested rangeland. At 3 days after treatment, the reduction in density was quite variable and ranged from 66 to $98.6 \%$ with average daily survival rates of about 0.70 to 0.24 , respectively. Efficacy did not appear related to stage of development at treatment time, so the mean of the $\mathbf{4}$ daily survival rates $(0.49)$ was accepted as the expected efficacy of the treatment. The survival rates during days 4 through 7 after treatment also were quite variable but averaged well below the natural rates in Table 1. It was therefore assumed that malathion had slight but measurable effects $(S=0.93)$ during days 4 through 7 after treatment.

Malathion was considered a candidate treatment for only a relatively short interval of time. The earliest experiment in Table 2 was successful against predominantly 5th instar nymphs (about day 14 of the destructive period) but early treatments are risky because they can essentially be negated by factors like cool weather or precipitation after application. Treatments should not be applied after oviposition begins (after about day 35 of the destructive period) for 2 reasons: most of the potential current-season forage destruction will already have occurred, and the potential for preventing infestation during the following season will have diminished. Therefore, the malathion treatment was considered an option only for the approximate period of days 14 to 34 , inclusive, of the destructive period.

The efficacy of malathion applied on successive days to the infestations of Table 1 was estimated as follows. The daily survival rate for day 1 of the destructive period (for day 1 of the 4th instar stage) until the day of treatment was the natural rate listed in Table 1 , for the first 3 days after treatment was 0.49 , for days 4 through 7 after treatment was 0.93 , and was again the natural rate there-

Table 2. Survival of grasshopper populations at 3 and 7 days after treatment with $584 \mathrm{ml} \mathrm{of} 95 \%$ technical malathion/ha, and estimation of average daily survival rates (an elaboration of data published by J.A. Onsager and P.C. Mazuranich in Insecticide and Acaricide Tests (IAT).

\begin{tabular}{|c|c|c|c|c|c|}
\hline \multirow[b]{2}{*}{ IAT reference } & \multirow{2}{*}{$\begin{array}{c}\text { Stage of } \\
\text { grasshopper development } \\
\text { at treatment }\end{array}$} & \multicolumn{2}{|c|}{ Average proportion of grasshopper survival (p) } & \multicolumn{2}{|c|}{ Average daily survival rate (S) } \\
\hline & & $\overline{3 \text { days after treatment }}$ & 7 days after treatment & days $0-31$ & days $4-7^{2}$ \\
\hline $\begin{array}{ll}1978 & 3: 132 \\
1978 & 3: 132-133 \\
1979 & 4: 144 \\
1980 & 5: 200\end{array}$ & $\begin{array}{r}91 \% \text { adults } \\
53 \% \text { adults } \\
7 \% \text { adults }\end{array}$ & $\begin{array}{r}0.16 \\
.34 \\
.01 \\
.10\end{array}$ & $\begin{array}{c}0.11 \\
.33 \\
.10^{3} \\
.06\end{array}$ & $\begin{array}{r}0.55 \\
.70 \\
.24 \\
.46 \\
\end{array}$ & $\begin{array}{r}0.91 \\
.99 \\
.88 \\
\end{array}$ \\
\hline & & & Mean & .49 & .93 \\
\hline
\end{tabular}

IS $=\sqrt[3]{\mathrm{p}_{3}}$

${ }_{2 S}=\sqrt[4]{p_{7} / p_{3}}$

3Aberrant due to immigration 
after. Benefits of treatment were then estimated as described. Results for 2 levels of infestation, expressed as percent reduction in forage destruction, are shown in Figure 1.

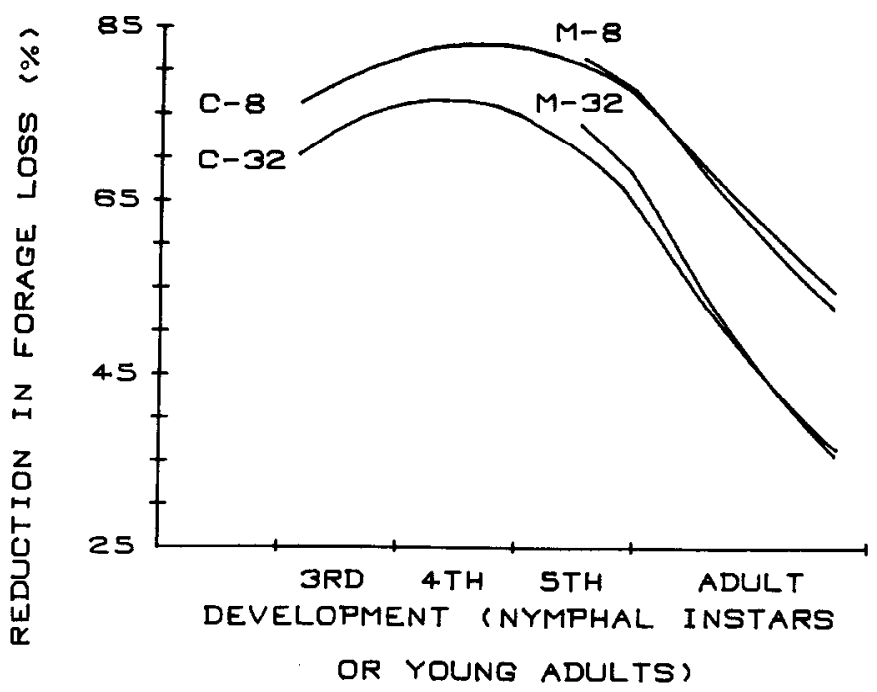

Fig. 1. Relationships between stage of grasshopper development at time of treatment and percent reduction in forage loss following treatments with malathion (M) or carbaryl (C) applied to infestations that averaged 8 or $32 / \mathrm{m}^{2}$ at the beginning of the 4th nymphal instar.

\section{Efficacy of Carbaryl}

Table 3 summarizes results from experiments where the Sevin-4oil formulation of carbaryl was applied at $0.56 \mathrm{~kg}$ of toxicant $/ \mathrm{ha}$ to 3 different life stages of grasshoppers on rangeland (Onsager 1978). At 7 days after treatment, the reductions in density ranged from 70 to $94 \%$ and were directly related to the time of treatment. Therefore, average daily survival rates from the 7-day period after treatment were estimated for different treatment dates by linear regression; i.e., $S=0.79333-0.0056500(i)$, where $i=$ day of the destructive period when the treatment was applied. The survival rates for days 8-14 after treatment suggested that the early treatments caused some mortality during the 2 nd week after treatment, so $S$-values for that interval also were estimated by regression; i.e., $S=0.93344+0.0014014(i)$. However, in order to prevent extrapolation errors, the latter rates were not allowed to exceed estimated natural survival rates for untreated populations of the same density.

Carbaryl was considered a candidate treatment for a relatively long interval of time. The earliest treatments reported in Table 3 were successfully applied about 10 days before the beginning of the destructive period $(i=-10)$, and late treatments can confidently be applied up to within 1 week of oviposition $(i=28)$. The relative efficacy of carbaryl treatments at intervals between $i=-10$ and $i=$ 28 , inclusive, was estimated similarily as for malathion treatments.
Exceptions were that survival rates after treatment were calculated by regression and were applied for a 14-day rather than a 7-day period. Results for 2 levels of infestation, expressed as percent reduction in forage destruction, are shown in Figure 1.

\section{Results}

Economic analysis is accomplished by comparing treatment costs versus the value of forage that was saved. A computer program that allows user input of cost-benefit data is available in BASIC language from the author. For demonstration purposes, it is here assumed that $364 \mathrm{~kg}$ of forage constitutes an AUM, and an AUM that is saved from destruction by grasshoppers has a marginal value product of $\$ 14$. This value is for illustrative purposes only; readers could use any value they thought appropriate.

In 1981, malathion treatments cost an average of $\$ 3.58 /$ ha in 2 cooperative control programs executed by APHIS in Wyoming and Oregon (unpublished data available from APHIS). Therefore, a malathion treatment must save $93 \mathrm{~kg} / \mathrm{ha}(\$ 3.58 / \mathrm{ha} \times 364$ $\mathrm{kg} / \$ 14)$ or $0.25 \mathrm{AUM} / \mathrm{ha}(93 \mathrm{~kg} / \mathrm{ha} \times 1 \mathrm{AUM} / 364 \mathrm{~kg})$ to be efficacious. That savings did not occur for treatments applied after days $15,21,29$, and 32 of the destructive period for infestations that initially were $6,8,16$, and 324 th instars $/ \mathrm{m}^{2}$, respectively. Treatments applied on or before the aforementioned days were potentially efficacious, so the EILs were estimated as the densities that existed on those days; i.e., as $4.54,5.06,6.62$, and 8.6 grasshoppers $/ \mathrm{m}^{2}$, respectively. The relationship between time of treatment and EIL is illustrated in Figure 2.

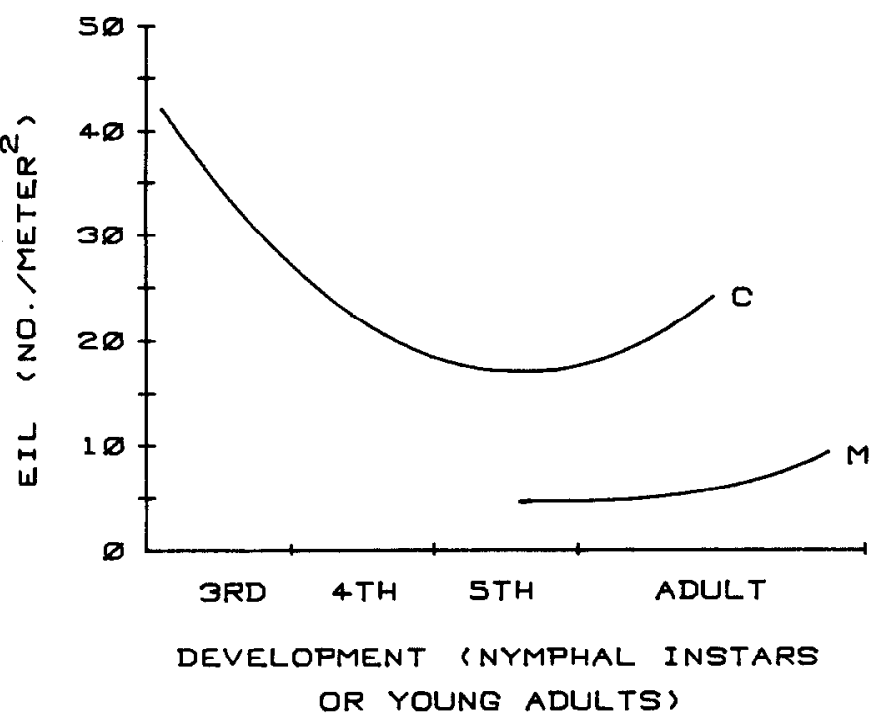

Fig. 2. Relationships between stage of grasshopper development at time of treatment and economic injury level (EIL) for treatments with malathion (M) or carbaryl (C). (In $E I L_{\mathrm{M}}=2.012-0.0642 \mathrm{i}+0.00213 \mathrm{li}^{2}$ and $E I L_{\mathrm{c}}=$ $27.05-1.47 \mathrm{l} \mathrm{i}+0.049 \mathrm{i}^{2}$, where $\mathrm{i}=$ number of days after beginning of the $4 t h$ instar.)

Table 3. Survival of grasshopper populations at 7 and 14 days after treatment with $0.56 \mathrm{~kg}$ AI of carbaryl/ha, and estimation of average daily survival rates (an elaboration of data published by Onsager, 1978).

\begin{tabular}{|c|c|c|c|c|c|c|}
\hline \multirow{2}{*}{$\begin{array}{l}\text { Stage of grass- } \\
\text { hopper development } \\
\text { at treatment }\end{array}$} & \multirow{2}{*}{$\begin{array}{c}\text { Time relative } \\
\text { to destructive period } \\
\text { (days) }\end{array}$} & \multicolumn{2}{|c|}{ Average proportion of grasshoper survival (p) } & \multicolumn{3}{|c|}{ Daily survival rate (S) } \\
\hline & & 7 days after treatment & 14 days after treatment & days $0-71$ & days & $8-14^{2}$ \\
\hline $\begin{array}{l}51 \% \text { in } 2 \text { nd \& } 3 \text { rd instar } \\
57 \% \text { in } 4 \text { th \& } 5 \text { th instar } \\
85 \% \text { in adult stage }\end{array}$ & $\begin{array}{r}-10 \\
9 \\
21\end{array}$ & $\begin{array}{r}0.303 \\
.146 \\
.057\end{array}$ & $\begin{array}{r}0.174 \\
.091 \\
.046\end{array}$ & $\begin{array}{r}0.84 \\
.76 \\
.66\end{array}$ & $\begin{array}{r}0.92 \\
.93 \\
.97\end{array}$ & \\
\hline
\end{tabular}

is $=\sqrt[7]{p_{7}}$

${ }_{2} \mathrm{~S}=\sqrt[7]{\mathrm{p}_{14} / \mathrm{p}_{7}}$ 
The above EILs are valid only if the forage saved from destruction is harvestable and will support at least $0.25 \mathrm{AUM} / \mathrm{ha}$. In other words, treatment costs cannot be quickly recovered if grazing by grasshoppers has already approached or exceeded the desired carrying capacity. For example, a treatment may be efficacious against a light infestation $\left(4.5 / \mathrm{m}^{2}\right)$ in a habitat where the carrying capacity is $0.35 \mathrm{AUM} / \mathrm{ha}$, provided it is applied early enough (day 14 of the destructive period) so that only $0.1 \mathrm{AUM}$ is lost despite treatment. On the other hand, the same treatment against a dense infestation $\left(9 / \mathrm{m}^{2}\right)$ in the same habitat would be relatively worthless if applied so late (day 32) that grasshoppers had already consumed $0.4 \mathrm{AUM} / \mathrm{ha}$. Treatments will provide short-term profits only if the total carrying capacity is at least $0.30,0.35,0.49$, and 0.67 AUM/ha., respectively, for the aforementioned EILs. The relationship between time of treatment and minimum carrying capacity for economical malathion treatments is given in Figure 3.

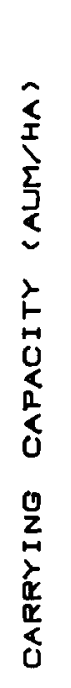
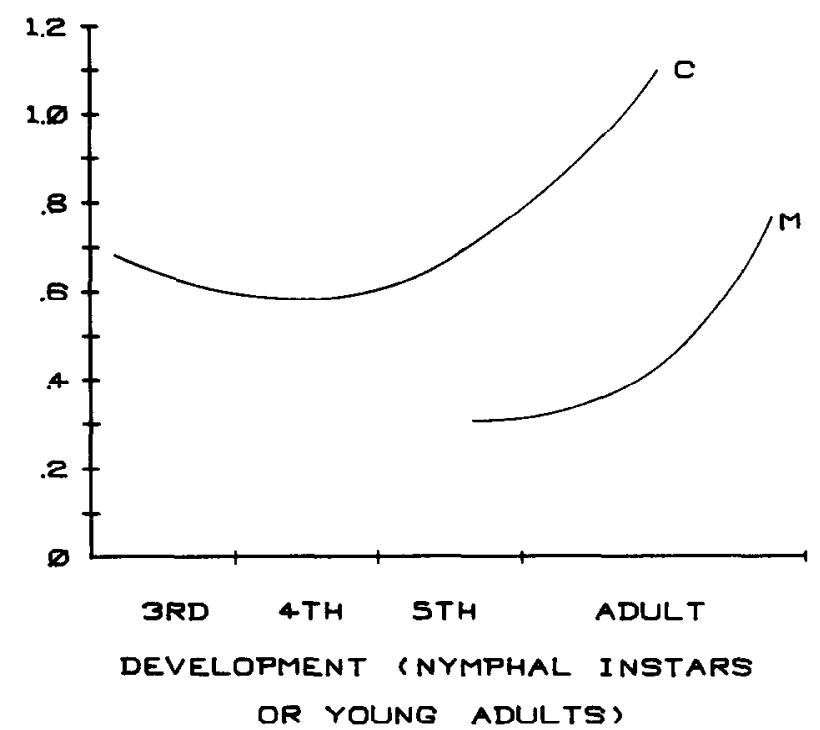

Fig. 3. Relationships between stage of grasshopper development at time of treatment and minimum total carrying capacity $(A U M /$ ha $)$ required to recover costs of treatment with malathion $(M)$ or carbaryl $(C)$. (In $A U M_{\mathrm{M}}=-0.560-0.0807 \mathrm{i}+0.00265 \mathrm{i}^{2}$ and $A U M_{\mathrm{C}}=0.588-0.00667 \mathrm{i}+$ $0.000952 \mathrm{2} 2$, where $\mathrm{i}=$ number of days after beginning of the 4th instar.)

Early treatments with carbaryl are obviously more effective in limiting forage destruction than later treatments with either carbaryl or malathion. It is equally obvious that late treatments of the 2 chemicals give nearly identical results.

In 1981, carbaryl treatments cost an average of $\$ 6.70 /$ ha in 2 cooperative control programs in Wyoming and Colorado (unpublished data available from APHIS). By using the same methodology as for malathion, it was estimated that a carbaryl treatment, to be efficacious, must save $174 \mathrm{~kg}$ of forage to support at least 0.48 AUM/ha. EILs for carbaryl also are illustrated in Figure 2. The minimum carrying capacity required to recover the costs of the carbaryl treatments ranged from about 0.6 to $1 \mathrm{AUM} / \mathrm{ha}$ (Fig. 3). For less intense stocking the carbaryl treatment is not economical.

\section{Discussion}

These results support the general contention of Onsager (1978) that early treatments with carbaryl are more efficacious than late treatments with either chemical. Regardless of density, the most effective time for carbaryl treatments was during the 4 th instar stage. The earliest malathion treatments also were the most economical. These provided control equivalent to the most effective carbaryl treatments. The primary advantage of carbaryl appears to be that maximum benefits can be derived from treatments over about a 3-week period during which efficacy of malathion has not been demonstrated. In contrast, maximum benefits from malathion are attainable only with perfect timing within a very narrow time frame. During the interval when either chemical may be used with confidence, malathion is clearly more efficacious than carbaryl in that almost identical grasshopper control can be achieved for about half the cost.

The type of weather associated with low forage production (hot and dry) unfortunately favors rapid development and high survival of grasshoppers. Furthermore, most of the damaging species prefer habitats with sparse vegetation and thus would be favored where range is overgrazed (Hardman and Smoliak 1982). Consequently, grasshopper populations are likely to be highest when forage production is lowest; the demand for forage by grasshoppers is likely to be greatest when ranchers can least afford to feed them, and the marginal value product of forage that is saved from destruction is disproportionately high during dry seasons.

If one expects short-term recovery of treatment costs, it seems imperative that any protective treatments be applied as early as possible in the season. The lower the carrying capacity, the more important it is to apply treatments early. These considerations do not preclude treatments to obtain long-range, intangible benefits (for example, to assure "rest" in a rest-rotation grazing system or to protect spring range from continued mid-summer grazing by grasshoppers). Intangible benefits, however, are beyond the scope of this study.

\section{Literature Cited}

Capinera, J.L., W.J. Parton, and J.K. Detling. 1983. Application of a grassland simulation model to grasshopper pest management on the North American shortgrass prairie. p. 335-344. In: W.K. Lauenroth, G.V. Skogerboe, and M. Flug (eds.) Analysis of Ecological Systems: State of the Art in Ecological Modelling. Elsevier Pub. Co. New York.

Hardman, J.M., and S. Smoliak. 1982. The relative impact of various grasshopper species on Stipa-Agropyron mixed prairie and fescue prairie in southern Alberta. J. Range Manage. 35:171-176.

Hewitt, G.B. 1979. Hatching and development of rangeland grasshoppers in relation to forage growth, temperature, and precipitation. Environ. Entomol. 8:24-29.

Hewitt, G.B., and J.A. Onsager. 1982. A method for forecasting potential losses from grasshoppers on northern mixed grass forages. J. Range Manage. 35:53-57.

Hewitt, G.B., and J.A. Onsager. 1983. Control of grasshoppers on rangeland in the United States-a perspective. J. Range Manage. 36:202-207.

Onsager, J.A. 1978. Efficacy of carbaryl applied to different life stages of rangeland grasshoppers. J. Econ. Entomol. 71:269-273.

Onsager, J.A. 1983. Model of relationships between survival rates, density, population trend, and forage destruction by instars of grasshoppers. Environ. Entomol. 12:1099-1102.

Onsager, J.A., and G.B. Hewitt. 1982. Rangeland grasshoppers: Average longevity and daily rate of mortality among six species in nature. Environ. Entomol. 11:127-133.

Onsager, J.A., N.E. Rees, J.E. Henry, and R.N. Foster. 1981. Integration of bait formulations of Nasema locustae and carbaryl for control of rangeland grasshoppers. J. Econ. Entomol. 74:183-187.

Poston, F.L, L.P. Pedigo, and S.M. Welch. 1983. Economic injury levels: reality and practicality. Bull. Entomol. Soc. Amer. 29:49-53.

Stern, V.M., R.E. Smith, R. van den Bosch, and K.S. Hagen. 1959. The integrated control concept. Hilgardia 29:81-101. 